\title{
Autonomy for obstetric nurse on low-risk childbirth care
}

Flávia Andréia Pereira Soares dos Santos 1 https://orcid.org/0000-0001-7271-8247

Bertha Cruz Enders 2

https://orcid.org/0000-0001-5258-4579

Rosineide Santana de Brito 3

https://orcid.org/0000-0001-7980-5693

Pedro Henrique Silva de Farias 4

D https://orcid.org/0000-0003-2246-4773

\author{
Gracimary Alves Teixeira 5 \\ (iD) https://orcid.org/0000-0002-6100-3796 \\ Dândara Nayara Azevêdo Dantas 6 \\ https://orcid.org/0000-0002-4759-9458 \\ Sonaira Larissa Varela de Medeiros 7 \\ https://orcid.org/0000-0002-9380-4678 \\ Adriana Souza da Silva Rocha 8 \\ iD https://orcid.org/0000-0002-0948-764X
}

1,4,7,8 Universidade Federal do Rio Grande do Norte. Hospital Universitário Ana Bezerra. Santa Cruz, RN, Brasil. CEP: 59535000. E-mail: pedro_hsilvaf@hotmail.com

2,3 Universidade Federal do Rio Grande do Norte. Centro de Ciências da Saúde. Departamento de Enfermagem. Natal, RN, Brasil.

5,6 Escola de Saúde. Universidade Federal do Rio Grande do Norte. Lagoa Nova, RN, Brasil.

\begin{abstract}
Objectives: to understand the cultural context presented in hospitals and its relation to the obstetric nurse's autonomous practice on low-risk childbirth care.

Methods: ethnographic research performed in three public maternities in Rio Grande do Norte, Brazil. Three managers and twenty-three obstetric nurses participated in this research.

Results: distinctive on cultural, organizational and structural aspects of the hospital institution interfering directly with the obstetric nurse's autonomous practice. Among these aspects, professional appreciation on low-risk childbirth care contributes for the nurse's autonomy

Conclusions: it was noticed that obstetric nurses undergo different contexts of action, which directly interfere with their autonomy on low-risk childbirth care and their decisionmaking abilities. It is necessary, then, to eradicate the relation of dominance and submission that it is still imposed by medical hegemony.

Key words Obstetric nursing, Professional autonomy, Midwifery, Delivery rooms, Women's health
\end{abstract}




\section{Introduction}

The obstetric nurse is a legally qualified professional with the ability to care for women during parturition processes. There are, however, issues in the hospital environment regarding to the nurse's autonomy on low-risk childbirth care taking place at the Sistema Único de Saúde (SUS) (National Health System) institutions.

Autonomy is understood as a determined degree of power, theoretically and/or of practical knowledge at the work environment, the competence in making choices, the ability to take action and responsibility in the decision-making. ${ }^{1}$ It is noteworthy that this is not a singular property of the subjects, but a significance that demands intersubjectivity, since it is based on a set of socially designed conditions. Therefore, it is associated with the issues related to the decentralizations of power, for it seeks to ensure a greater political participation of the subjects. ${ }^{2}$

In spite of the progress in the ministerial policies and mandates, as a guarantee of the Lei do Exercicio Profissional (Law on Professional Practice), which upholds the obstetric nurses' practice, their participation in childbirth care is still limited during the routine in the health services. 3 Thus, overcoming this reality, it still remains a challenge, since care for the parturient continues to be centered in the biomedical model, in which interventionism is habitual in institutions that assist women, ${ }^{4}$ with growth in all the regions in Brazil.5

It is necessary to broaden the discussion on this context, in which the practice of nursing takes place. In this perspective, it is necessary to understand the potential availability in organizational establishments to generate information about critical knots that prevent the obstetric nurse's effective participation during low-risk childbirth.

Therefore, it is inferred that the obstetric nurse's autonomy is directly related to his or her freedom on the decision-making while caring for the parturient, thus significantly contributing to the humanization on childbirth care.

Nevertheless, it is known that this participation is influenced by the existence of power relations in the health institutions, ${ }^{6}$ as well as by beliefs, values, relationships and meanings. 7 Thus, the obstetric nurses' decision-making on parturient care is mediated by the cultural issues presented at the workplace. ${ }^{8}$

It is observed that the nurse's performance is a social event with significant cultural influence, imposed by established power relations. ${ }^{7}$ For this reason, this study was developed around the central concept of culture, for it is believed there is something concealed that promotes or inhibits the obstetric nurse's autonomy. From this perspective, culture is defined as a web of meanings established by human beings, in which he or she views his or her world. This interpretative analysis of meaning is incorporated by social relations in a semiotic approach. ${ }^{9}$

In general, the contextual aspects surrounding the research problem of this investigation concerning the obstetric nurse's autonomy has prompted a question: how does the cultural context of the hospital institution relates to the obstetric nurse's autonomous practice on low-risk childbirth care?

Therefore, this study aims to understand the cultural context of the hospital institution and its relation to the obstetric nurse's autonomous practice on low-risk childbirth care. Thus, this study intends to contribute in strengthening the Obstetric Nursing with aspiring significant changes in the Obstetric health model, centered on a holistic vision and humanized care.

Currently, three models guide the paradigms of health care in Obstetrics: technocratic, humanistic and holistic. The technocratic model is based on the concept of separating the mind and body, as well as on the domination of machines over individual and collective beliefs. Opposing this concept, having a humanized model brings the idea of interconnection among the physical condition, the psychological components and the society. The holistic model on the other hand, combines the richest variety of approaches, indicating the influence of the body, mind, emotions, spirit, and environment in the healing process and human care. 10

However, it may be considered that the elements of the institutional culture influences the transformation regarding to reshaping healthcare models, as well as in social and power relations. These aspects establish an interface with the process of subjectivity and construction of professional identity, seeking autonomy in care for the parturient. Thus, the obstetric nurse's decision-making process and the consolidation on childbirth care models are challenging, for they depend on ethical aspects related to moral, cultural and social issues existent in the obstetric sector.

\section{Methods}

\section{Types of Study}

The ethnographic research was developed in three public maternities in Rio Grande do Norte, Brazil. 
The ethnography was chosen as a methodological reference for this investigation allowing the creation of concepts and explanatory relations through the comprehension or the construction of a network of meanings, built on the interrelationship, beliefs, and values of people in the institutional establishments. ${ }^{11}$

In relation to institutional establishments, it is important to emphasize that maternity 01 has 53 beds, of which 10 are for Prepartum, Childbirth and Postpartum suites (PCP), and the remaining beds are distributed among Pediatrics, Rooming-in, Clinical Surgery and Neonatology. The staff is composed of a multi-professional team for a 24 hour shift and obstetric nurses are exclusively for the PCP sector.

The second participating institution is organized in 16 PCP suites, three rooming-in wards, and a multi-professional team for the 24 hour shift. The obstetric nurses are not exclusively for the PCP sector. However, the third maternity has an obstetric center, but it does not have PCP suites. It has a 24 hour shift with a multi-professional team, though, only four obstetric nurses had a shift in the low-risk childbirth sector.

\section{Procedures}

The selection of three public maternities in the State of Rio Grande do Norte, Brazil, occurred due to the following criteria: to be well-established in assisting low-risk women in labor and to have obstetric nurses as part of the parturitive care process.

Three managers participated in this study, one from each maternity and 23 obstetric nurses who worked at one of these health institutions and met the following inclusion criteria: they were part of the obstetric sector and were included to care for women in low-risk parturitive process. Those who were on vacation, on medical leave or any other type of leave were excluded at the time of data collection.

The majority of the obstetric nurses were women with a predominance of 30 to 39 years old. In regard to professional training time, it was observed that in the investigated maternities there were professionals with a long time of proven expertise in obstetrics. In relation to the length of work experience, most of them stated that they had an extensive professional experience in obstetrics. In reference to the managers, they are professionals in the area of Obstetric Nursing, Speech Therapy and Medicine. Among them, two have been in management at the institution for two years and one about 11 years.

The data collection occurred from July to October 2016, through multiple sources: semi-structured interviews, participant observation, field diary and focus group. Two ethnographic, descriptive, and structural questions started the interviews with obstetric nurses: 'Speak about your experience in the decision-making process in the childbirth care at this institution' and 'How do you analyze the organization at this institution as a referral place for humanized childbirth?'

The interviews took place at the hospital, according to the informants' solicitation, except for a manager, who chose to be interviewed at his residence. In both locations, the data collection occurred calmly without any interruptions. Simultaneously, the participant observation occurred through a script that included eight observable indicators with the intention of guiding the data collection and mapping the obstetric nurses' work routine.

The researcher considered as a criteria during this technique, to collaborate with the identified situations that presented a risk or discomfort to the parturient. Observations occurred during day and night work shifts with an average of 12-hour period for each professional. The descriptions were related to structural, organizational, and cultural conditions, as well as behaviors, actions, specific activities, relationship and dialogues of the obstetric nurse. The participant observation is a method to obtain information in regard to a determined group of people's culture in their living environment. 12

After this stage, two contrasting questions arose to interview three managers from the institutions that were participating in this research, in order to confront the data collected: 'Could you talk about obstetric nurses' participation in the low-risk childbirth care at this institution?' And 'Speak about the role in management to promote the obstetric nurses' autonomy on low-risk childbirth care.'

In addition, the events taken place during the data collection were registered in the field diaries, such as informal conversation, expression of sadness, happiness, revolt, fear, insecurity and relation of dominance. Finally, the focal group technique was performed in a single session, where eight obstetric nurses participated, in order to discuss new questions originated by the semi-structured interviews and the participant observation, as well as to enable validation of cultural themes (concepts) that emerged during the phase on data analysis.

It is noteworthy that in order to assure confidential collected information, the participants' names were replaced by numbers and letters. Thus, the anonymity was guaranteed by using an alphanumeric code consisted by the initials of the profession/position (E for Enfermeiro (Nurse) and G for Gestor (Manager) ), followed by a cardinal number, such as 
E01.

The data were analyzed simultaneously to the data collection, according to the ethnography precepts, 12 thus, as the data were collected, concomitantly, they were organized, systematized and analyzed, to identify cultural domains and the emergence of new ethnographic questions. The participant observation, interviews and field diary subsidies were inserted in the Atlas.ti software, which was used for the qualitative analysis of the collected information.

Moreover, multiple sources of data and four stages were recommended in the analysis process: domains, taxonomic, componential and theme analysis. Of these, the emerged terms included corresponded to the subcategories, and the covered terms, referred to the categories. The semantic relation gave origin to these concepts. 12

Soon after, the domain analysis began, intending to identify symbolic domains/categories or symbols that could share cultural meaning concerning the obstetric nurse's autonomy on low-risk childbirth care. The next phase in the analysis was the elaboration of taxonomies, in which the data collection was analyzed in depth, constructing a hierarchy classification. At this stage, terms included in contrast were identified, giving a rise to the third level of the analysis, entitled componential, which represents the systematized quest for differences among symbols and helps the discovery of meanings. 12

Thematic analysis, which was the last and more refined stage, started in the immersion of the ethnographic data, while finalizing the domain, taxonomic and componential analysis process with the objective of identifying the cultural themes (concepts). Therefore, five cultural domains, a taxonomy, and a contrast arose through this research analysis process. The cultural mapping approach, which consists of the interlacing of the domains, defined three cultural themes (concepts), allowing the discovery of three covered terms, one of which was presented here and validated by the focus group participants, originating the central cultural theme: constructing the obstetric nurse's autonomy on low-risk childbirth care.

\section{Ethical Aspects}

The development of this research took place after the formal consent from the institutions, a favorable assessment of the Ethics and Research Committee (CEP) at the Universidade Federal do Rio Grande do Norte (UFRN), under CAAE number 55187716.9.0000.5537, and the Informed Consent Form (TCLE) was signed by the participants of this study.

\section{Results}

In the three maternities participating in this research, it was confirmed that the distinct cultural, organizational and structural aspects of the hospital institution directly interfere with the obstetric nurse's autonomous practice on low-risk childbirth care.

Thus, among the cultural aspects recognized in the informants' practice scenarios of this study, the biomedical model in the parturitive process was emphasized, as it can be seen in the following report:

"Often, when we arrive for our shift, she is already on the serum, she's already on oxytocin. They tell her to lie in bed, and when we arrive, we try to change that whole paradigm, but we can't." (E18)

The institutional policies of two maternities investigated were linked to the hegemony of this healthcare model. As a result, this makes it difficult for the obstetric nurse as an agent, change in the parturitive process, as it can be perceived in the nurses' and managers' statements:

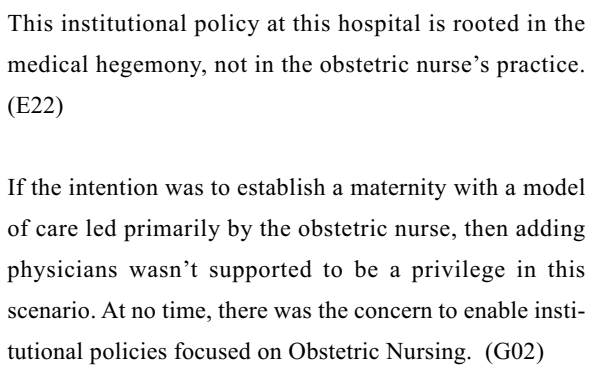

The central mechanism of medical category domination of the institution implies significant difficulties in the decision-making power, not only the obstetric nurse, but also the team, that begins to act unstructured. This was highlighted by one of the interviewees saying that

"[...] faces a loose team, physicians on shifts with his or her own conduct, and very heterogeneous nurses." (E09)

In order to alter this hegemony, based on a proposal of a humanized obstetrical model, it is necessary to change the institutionalized beliefs and values, even though that may trigger conflicts among health professionals, given the possibility to change their respective work processes, as seen in the following speech:

“They are professionals who don't agree with changes. 
They are not against obstetric nurses, but there are also simple things: they are against the bed, against the PCP system (in the same suite) [...] They are people who has a closed mind to change, they're settled in their system and they don't want things to change." (EO2)

The biomedical culture, which supports the medicalization process of childbirth, is still present in two maternities researched, in which these maternities are unable to provide effective conditions and attitudes consistent with good practices on humanization of childbirth.

It was noticed, through the participant observation, in one of the maternities researched, for example, the inexistence of non-pharmacological methods, as well as inadequate environment to promote humanized childbirth. In addition, the organization of the service follows the traditional line of care, reinforcing the division of work among those who are in charge and those who execute actions.

I don't think this is a well-established place for humanized childbirth. Sometimes, the patient is placed on a chair in the hallway because there are no more hospital beds [...] There aren't non-pharmacological methods. We try to humanize the process because there is a law but in terms of structure and conditions offered, there aren't offered any. (E20)

Another aspect to be considered in the context of professional practice, which directly impacts the obstetric nurse's autonomy, is the overcrowding of certain services, a situation that is aggravated by inadequate dimension, resulting in overload work for these nurses. The following statements properly portray this reality:

There aren't enough staff to follow up. So, often $[\ldots]$ even at the time of childbirth you can't be present, because you're doing another activity $[\ldots]$ we end up taking on all the patients from several sectors, and we can't really do what is within our competence. We also have overcrowding $[. .$.$] This way, care won't be as humanized as$ we'd like it to be. (E14)

It is noteworthy mentioning the appraisal of the obstetric nurse's professional identity on low-risk childbirth care in a maternity, since it contributes to the autonomy of these professionals. For instance,

This work developed here is very beautiful, because nurses really see themselves as obstetric nurses, able to provide care during labor, discuss with the medical team and be heard [...]. In here, I feel fulfilled and comfortable because I feel protected and supported, Leaving here, now

I'm not so sure (E09).

Institutional culture, besides promoting professional autonomy, manages to establish important interaction with other professionals, from a collaborative and multi-professional service perspective, as observed in the following statement:

The obstetric nurses, in this hospital, have enough autonomy in the decision-making to evaluate, to partake, to assist a childbirth and, when identifying any dystocia, they for the physician. They (the physicians) have a lot of confidence in the obstetric nurses, and so do the other professionals. We really discuss the cases with the whole team. There is information exchanging among our areas. (E01)

Associated to this, adequate working conditions favor the development of good practices on childbirth care to be in accordance with humanization.

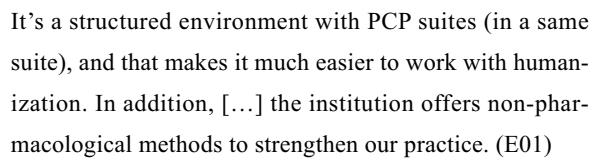

\section{Discussion}

Based on the collected data analysis, it can be inferred that the cultural context present in the institutional hospital is related to the obstetric nurse's autonomy on low-risk childbirth care in several forms.

One of the cultural characteristics identified in the practice scenarios of the informants of this study was the biomedical model as a preponderant way of conducting the parturitive process. This model is characterized by medical hegemony and the appraisal of techniques that do not appreciate the active participation of women in childbirth, as exemplified in the E18 speech. For this specific reason, does not favor the protagonism of women, an essential aspect for humanized childbirth care. 13

It was demonstrated that the biomedical model, by establishing routines of physician-centered care and the appreciation of procedures and high technologies, hinders the availability of humanized care during childbirth. ${ }^{14}$ From this perspective, childbirth is seen as a pathological process, imbued with interventions in order to maintain control power of the parturient, 15 and not as a physiological and natural event, capable of requiring little or no intervention. 13

A study developed in Rio de Janeiro ${ }^{14}$ states that 
hospital culture, centered on the biomedical model, may influence in how the obstetric nurses provide care. Hence, labor care will use all the available technological means in obedience to the biomedical model. Therefore, childbirth care is anchored in a system of norms and values of its own, with distinct processes of production and reproduction of dominance relations. 16

Thus, the interviewees identified interference of the technical hegemony over their professional identity, as their role suffers subordination and dependence to the medical conceptions. Consequently, a relationship of domination and subordination, without cooperation is developed between physicians and nurses. Therefore, in the symbolic context of hospital performance, a hierarchical position is established among the professional categories. 16

In addition to the domination it establishes over the obstetric nurse and other health professionals, medicine also has strong upward influence on the institution itself and on the patients. The participants of this study recognized the necessity to change the current paradigm for labor care, based on non-interventionist models.

Nevertheless, adopting the proposal of a humanized obstetric model means changing institutionalized beliefs and values which has shown to trigger conflicts among health professionals. Thus, obstetric nurses' performance is often dependent on the medical staff on shift and on the biomedical model established at the maternities.

The humanization on healthcare emerges as an alternative to transform the current scene in SUS, requiring changes in several aspects, in order to overcome the difficulties to access quality services. This situation extends to women's health, especially when care is analyzed based on good practices on childbirth care. 17

From this point of view, humanization could be conceived as a reflexive process, focused on values and principles that lead to a dignified, supportive and welcoming care, based on an ethical stance and respectful of human dignity. 18

Regarding to the participants' speech, it is possible to perceive an inconsistency between the practice experienced by the obstetric nurses and the ministerial guidelines that address the childbirth care. This is due to the fact that some institutions show signs of dichotomy between the perspective of the humanistic care model and the pressures arising from medical control in the management of care processes.

This reality has caused difficulties in the strengthening the consolidation of the teamwork in the health services, due to the isolated and independent hegemonic model. For this reason, there is the fragility of the obstetric nurses' cohesion in their conduct with the objective of advancing in their profession.

It should be noted that, influenced by the socialization and cultural history of the institution, professional practice involves dynamic processes capable of causing interference in its identity, which is then constructed and reformulated with the interaction established among social actors, through the meaning that human beings verify themselves or those who are attributed by others. ${ }^{19}$ And so, the professional identity of the obstetric nurse tends to be differentiated when this social actor experiences contexts with cultural characteristics of the professional appreciation. 14

Cultural differences, values, meanings and symbolic systems of a group are increasingly visible and relevant in the field of social practices. Therefore, it is imperative to learn the origin of these issues and to define mechanisms that point to which direction they may lead.20 For this reason, it is worth pointing out that the institutional culture of one of the maternities develops strategies aimed to the professional identity of the obstetric nurse on low-risk childbirth care.

According to the statements presented in the results, the participants were able to individually and collectively construct a professional identity as they wished to achieve in the care of women in parturition process. It was verified that the strategies referenced by the interviewees, in the aforementioned institution, were counter-hegemonic and focused on results that promote the humanistic model, as well as the autonomy of the obstetric nurse on low-risk childbirth care.

Furthermore, they can establish important interactions with other professionals, from the perspective of collaborative and multi-professional service. In order to do so, it is necessary to move forward in the relations among the different categories to avoid overlapping among them and to collaborate with each other as members of a single team whose final commitment is directed towards the patient's care. ${ }^{21}$

Hence, it is necessary to analyze the specific organizational arrangements in nursing practice, the established social relations and the system of value that will grant meaning. Social relations established in the context of professional activity distribute to power, institutionalize forms of action in different spaces and areas of knowledge, besides shaping daily activities of social actors. 22

These relationships go beyond technical trust, in 
so far as they arouse the feeling of being part of a larger purpose. They contribute to the autonomy of the obstetric nurse and to professional satisfaction and, in a positive way, reflect on the organizational climate of the institution. Thus, they allow suitable working conditions for nursing practice development.

The Ministry of Health considers the environment, access to non-pharmacological methods of pain relief, participation of a multi-professional team, and the performance of the obstetric nurse with autonomy for principles and guidelines of humanization. 17

Thus, another aspect to be mentioned concerns the adequate number of professionals. According to the Ordinance Number 11, dated on January 7, 2015, for five PCP suites, there should be an obstetric nurse as a care coordinator and a nurse, with a coverage of 24 (twenty four) hours a day. 4

The information obtained in this study shows the different structural, organizational and cultural conditions that, depending on the place of performance, promote or inhibit the autonomy of the Obstetric Nursing in the hospital context. Thus, the institutional context of services is not limited to the set of structural and technological provisions. Therefore, it is also imperative to reflect on the relations that comprise the experience of the actors who witness the reciprocal strategies of social order and power, on which services are constructed.23 As historical progression occurs, the systems are enacted within institutions, aiming to establish disciplinary order. 24

In this approach, it was confirmed that one of the maternities researched has been conducting over the years regarding the insertion of the obstetric nurse in the childbirth scene, in order to consolidate the humanistic model in care. This reality is acknowledged not only by the professionals who work there, but also by their managers.

The dissemination of the institutional culture, regarding the change of the care model and the autonomy of the obstetric nurse in conducting lowrisk childbirth, is already a reality in the state of Rio Grande do Norte. However, despite this recognition, obstetric nurses presented signs of difficulties in their decision-making power, a fact that can trigger an internal crisis in the institutional culture already established in the given maternity, due to the hegemony of the Cartesian model still present in the obstetric area.

Crisis is understood as the set of probable cultural changes that result in new perceptions about reality and social practices. Thus, internal stability, as well as the way of perceiving the meaning of what is experienced daily, may undergo changes, since these are phenomena capable of causing disorder of what appears to be stable. ${ }^{25}$

In this point of view, the challenge was noticed to portray the reality experienced by obstetric nurses in public maternities in the state of Rio Grande do Norte, due to the different contexts and their infinite possibilities which directly interfere with the professional's decision-making power.

It was observed that these spaces are constituted by structural conditions, organizational practices and, above all, by cultural aspects, such as values perpetuated by the institution and beliefs of the individuals involved, which are capable of enabling the development of dependence or autonomous practice of the obstetric nurse. Also, it was seen that this universe unleashes a network of social and power relations, interspersed by the diverse feelings that permeate the obstetric practice.

\section{Final considerations}

The trajectory of this study found that obstetric nurses experience different contexts of action, which directly interfere in their autonomy on low-risk childbirth care. These spaces cover different structural conditions, organizational processes and, above all, cultural aspects that, depending on the place, contribute for them to have freedom in their decision-making power, in order to remove the relations of domination and submission still imposed by medical hegemony.

Therefore, "plunging" into the social world of the obstetric scenario made it possible to understand that it is a medium permeated by beliefs, values and interactions, which shape the knowledge power of multiple professions and establish relationships capable of generating a dense network of not only tension, conflicts, contradictory negotiations and feelings, but also of learning.

The consideration on the obstetric nurse's role in managing the parturition process revealed, beyond limits, the possibility of the appreciation of the professional identity on low-risk childbirth care, aspiring the development of his or her autonomy, having as a starting point the cultural context where the phenomenon happens, since the professional practices have traces of the cultural universe of the institution in which they belong.

Therefore, this study has brought relevant contributions to address difficulties in the perspective of autonomous obstetric nurses, since it discussed points that consists in the articulation between 
culture and autonomy, aiming at the subjectivities of this professional on low-risk childbirth care.

Thus, the shared experiences and inherited values exert an influence on daily activities, in order to promote or inhibit autonomy, embodied by the individual, that is, from the attitude of the individual to the action and from his or her power in relation to other people present at the institution.

The interviewees in this study displayed difficulties of expression and clarification of the meanings. However, in an attempt to minimize these limitations, the researcher provided a private and comfortable environment capable of promoting the free expression of feelings, perceptions and meanings.

\section{Authors' Contribution}

Santos FAPS, Enders BC and Brito RS - contributed to the design and delineation of the research, the data collection, the analysis and interpretation, the writing of the article and the approval of the final version. Farias PHS, Teixeira GA, Dantas DNA, Medeiros SLV and Rocha ASS - the writing of the article, critical review and the approval of the final version. All authors approved the final version of the manuscript.

\section{References}

1. McKay S. The route to true autonomous practice for midwives. Nurs Times. 1997; 93 (46): 61-2.

2. Flickinger HG. Autonomia e reconhecimento: dois conceitos-chave na formação. Educação. 2011; 34(1): 7-12.

3. Amestoya SC, Backes VMS, Thofehrn MB, Martini JG, Meirelles BHS, Trindade LL . Conflict management: challenges experienced by nurse-leaders in the hospital environment. Rev Gaúcha Enferm. 2014; 35 (2): 79-85.

4. Brasil. Portaria $n^{0} 11$ de 7 de janeiro de 2015. Redefine as diretrizes para implantação e habilitação de Centro de Parto Normal (CPN), no âmbito do Sistema Único de Saúde (SUS). Diário Oficial da União [DOU]. Brasília, DF; 2015. [acesso em 30 out 2016]. Disponível em: http://www.saude.ba.gov.br/portalcib/images/arquivos/Port $\operatorname{arias} / 2015 / 01$ janeiro/PT_GM_N_11_01.01.2015.pdf

5. Rodrigues JCT, Almeida IESR, Neto AGO, Moreira TA Cesariana no Brasil: uma análise epidemiológica. Rev Multitexto. 2016; 4 (1): 48-53.

6. Silva ALS, Nascimento ER, Coelho EAC. Nurses practices to promote dignity, participation and empowerment of women in natural childbirth. Esc Anna Nery [online]. 2015; 19 (3): 424-31.

7. Caus ECM, Santos EKA, Nassif AA, Monticelli M. The process of giving birth assisted by obstetrician nurse in a hospital context: mean for the parturients Esc Anna Nery [online]. 2012; 16 (1): 34-40.

8. Baliza MF, Bousso RS, Poles K, Santos MR, Silva L, Paganini MC. Factors influencing intensive care units nurses in end-of-life decisions. Rev Esc Enferm USP. 2015; 49 (4): 572-9.

9. Geertz C. A interpretação das culturas. Rio de Janeiro (RJ): Editora Guanabara Koogan; 1989.

10. Davis-floyd R. The technocratic, humanistic and holistic paradigms of childbirth. Int J Gynaecol Obstet. 2001; 75 (Suppl 1): S5-S23.

11. Spradley JP. The ethnographic interview. New York: Iolt, Rinehart and Winston; 1979.

12. Spradley JP. The participant observation. New York: Iolt Rinehart and Winston; 1980.
13. Silva U, Fernandes BM, Paes MSL, Souza MD, Duque DAA. Nursing care experienced by women during the childbirth in the humanization perspective. J Nurs UFPE [online]. 2016; 10 (4): 1273-9.

14. Nicácio MC, Heringer ALS, Schroeter MS, Pereira ALF. Percepção das enfermeiras obstétricas acerca de sua identidade profissional: um estudo descritivo. Online Braz J Nurs [online]. 2016;15 (2): 205-14.

15. Maia MB. Humanização do parto: política pública, comportamento organizacional e ethos profissional. Rio de Janeiro: Fiocruz; 2010.

16. Carapinheiro G. Saberes e poderes no hospital: uma sociologia dos serviços hospitalares. Porto : Afrontamento Ltda; 1993

17. Brasil. Ministério da Saúde. Programa de Humanização do Parto: Humanização no pré-natal e no nascimento. Brasília, DF; 2002.

18. Onias JMTC, Carvalho JA, Escobar KAA. Humanização e integralidade da atenção à saúde reprodutiva da mulher no Sistema Único de Saúde - SUS. Rev Cient ITPAC [online]. 2013; 6 (1): 1-9.

19. Cardoso MIST, Batista PMF, Graça ABS. A identidade do professor: desafios colocados pela globalização. Rev Bras Educ. 2016; 21 (65): 371-90.

20. Veiga-Neto A. Michel Foucault e os estudos culturais. In: Costa MV (org.). Estudos culturais em educação: mídia, arquitetura, brinquedo, biologia, literatura, cinema. Porto Alegre: UFRGS; 2000. p.288

21. Przenyczka RA. The paradox of freedom and autonomy in nurses' actions. Texto \& Contexto Enferm. 2012; 21 (2): 427-31.

22. Smith DE. Institutional Ethnography: Using Interviews to Investigate Ruling Relations. In: Smith DE (Org.). Institutional Ethnography as Practice. Lanham: Rowman \& Littlefield Publisher; 2006. p. 15-44.

23. Crozier M, Friedberg E. L'acteur et le système : Les contraintes de l'action collective. Paris: Du Seuil; 1977. 
24. Foucault M. Vigiar e punir: nascimento da prisão. Tradução de Raquel Ramalhete. 35 ed. Petrópolis: Vozes; 2008.

25. Harvey D. Espaços urbanos na aldeia global: reflexões sobre a condição urbana no capitalismo no final do século XX. Cadernos de Arquitetura e Urbanismo. Minas Gerais: PUC; 1996.

Received on August 28, 2018

Final version presented on February 25, 2019

Approved on May 09, 2019 